\title{
Empirical Study on Our Country's Initial Public Offerings Efficiency in Inquiry System -Based on Stochastic Frontier Analysis
}

\author{
1,a Zhang Jian ${ }^{2, b}$ lihoujian \\ ${ }^{1,2}$ School of economics and management, Sichuan Agricultural Uniersity, ChengDu, Sichuan \\ 610000, China
}

A,b jefeer@163.com

Keywords: Initial public; pricing efficiency; stochastic frontier analysis; fall on.

\begin{abstract}
.
The paper regards 647 of Initial Public Offerings (IPO) companies on SMEs board from June 2006 to November 2012 as research samples, utilizes stochastic frontier analysis to carry out an empirical test on reform of initial public offering for three times and primary market's pricing efficiency, and explains the phenomenon of falling on its first day of trading. Research results show that IPO primary market pricing in inquiry system has obvious upper boundary phenomenon for overall samples. Before the first reform in June 2009 and after the third reform in May 2012, because China Securities Regulatory Commission(CSRC) conducts "window operation" on offering price, resulting in the generation of deliberate under pricing in primary market. Offering primary market pricing isn't fully efficient, while depression of secondary market is the primary cause of resulting in falling on its first day of trading for initial closing price.
\end{abstract}

\section{Introduction}

Under pricing of Initial Public Offerings (IPO) refers to a phenomenon that primary market offering price is obviously inferior to secondary market initial bargain price. Such a phenomenon exists extensively in global security exchange market, especially for China's A share market.

In practice, IPO process is the excavation and discovery process of IPO inherent value. It is hard to estimate IPO inherent value before issuing, so the underpricing phenomenon that systematicness of primary market issuance pricing is inferior to inherent value can't distinguish from the underpricing phenomenon caused by irrational factors of secondary market's investors. IPO underpricing rate calculated by using initial closing price simply may overestimate influences of non-rational emotion of secondary market's retail investors. The paper, based on Stochastic Frontier Analysis that is frequently used by production economics, estimates IPO inherent value, inspects primary market's pricing efficiency in SMEs board after 2005 inquiry system, and analyzes influences of issuing system in inquiry stage on IPO pricing efficiency.

\section{Research Design and Sample Selection}

Stochastic Frontier Analysis Model: Farrell (1957) is the first one who uses Stochastic Frontier Analysis to analyze production economics basically. Practical production efficiency may be superior or inferior to estimated value, which is above average production efficiency and is obtained by estimating input-output by using Ordinary Least Squares (OLS). When economic theory or economic model needs to draw a conclusion that how do the maximum output achieved under the constraints of established input and technology, or given output level and technological level realize the minimum input cost, average output or average cost obtained by utilizing Ordinary Least Squares(OLS) can’t better depict production frontier(maximum output or minimum cost). For this reason, assume that function of IPO issue price is as follow:

$\mathrm{p}_{i}=f\left(\mathrm{x}_{\mathrm{i}} ; \beta\right)$ 
Here, ${ }^{x_{i}}$ is the factor of IPO pricing, ${ }^{P_{i}}$ is the IPO issuance pricing, and $\beta$ is a parameter that requires for estimation. Assume that the pricing efficient parameter is $T E_{i}$, and $T E_{i} \in[0,1]$. Therefore, the function of IPO issuance pricing is:

$\mathrm{p}_{i}=f\left(\mathrm{x}_{\mathrm{i}} ; \beta\right) T E_{i}$

Obviously, when $^{T E_{i}}=1$, IPO pricing is fully efficient. For publishers, it can realize the biggest issue returns $f\left(\mathrm{x}_{\mathrm{i}} ; \beta\right)$, which is called as the deterministic boundary of IPO issuing price. When $T E_{i}<1$, pricing is not fully efficient. Assume that the actual pricing that we can observe is $\mathrm{P}_{0}$, and $\mathrm{P}_{0}<f\left(\mathrm{x}_{\mathrm{i}} ; \beta\right)$. Aigner and Chu advise to add a nonnegative random variable in pricing function, which can measure pricing efficiency. Therefore, pricing function is converted to:

$$
\mathrm{p}_{0}=f\left(\mathrm{x}_{\mathrm{i}} ; \beta\right)-\mu_{i}
$$

Assume that pricing function satisfies the Cobb-Douglas $f\left(\mathrm{x}_{\mathrm{i}} ; \beta\right)=\beta_{0} \mathrm{X}_{1}^{\beta_{1}} X_{2}^{\beta_{2}} \llbracket X_{k}^{\beta_{k}}$, and then

$$
\operatorname{lnp}_{\mathrm{i}}=\beta_{1} \ln \mathrm{X}_{1}+\beta_{2} \ln \mathrm{X}_{2}+\llbracket+\beta_{\mathrm{k}} \ln \mathrm{X}_{\mathrm{k}}-\mu_{\mathrm{i}}
$$

Existing flaw of formula (1) is that some random disturbance terms are independent of corporate profitability and management level, etc. factors. Therefore, no matter how the company improves management level or increases profits, it also can't eliminate these random disturbance terms. For instance, natural factors of the earthquake, etc., can't be controlled by the management. The indicator of primary market's pricing efficiency estimated by adopting formula (1) can't distinguish from influences of man-made controllable factors and man-made uncontrollable natural factors on corporate production efficiency. Based on this disadvantage, Aigner, Lovell and Schmidt (1997) modify the pricing function, showing as follow: $\mathrm{p}_{i}=f\left(\mathrm{x}_{\mathrm{i}} ; \beta\right) T E_{i} \exp \left(\mathrm{v}_{\mathrm{i}}\right)$, after taking the logarithm for both sides: $\ln \mathrm{p}_{\mathrm{i}}=\ln \left(f\left(\mathrm{x}_{\mathrm{i}} ; \beta\right)\right)+\ln \left(T E_{i}\right)+\mathrm{v}_{\mathrm{i}}$, define $\mu_{i}=-\ln \left(T E_{i}\right)$. Meanwhile, $f\left(\mathrm{x}_{\mathrm{i}} ; \beta\right)$ satisfies Cobb-Douglas production function, then:

$\ln \mathrm{p}_{\mathrm{i}}=\beta_{0}+\sum_{j=1}^{k} \beta_{j} \ln \left(\mathrm{x}_{\mathrm{ji}}\right)+\mathrm{v}_{\mathrm{i}}-\mu_{\mathrm{i}}$

Here, ${ }^{x_{j i}}$ is the factor of impacting IPO pricing, $\ln \mathrm{p}_{\mathrm{i}}$ is the logarithmic form of IPO pricing, ${ }^{\mathrm{i}_{\mathrm{i}}}$ is the random error, and $-\mu_{\mathrm{i}}$ is the unilateral error, which is used for measuring the unavailability of IPO pricing. Assume that random error ${ }^{\mathrm{v}_{\mathrm{i}}}$ satisfies the classical assumption $\mathrm{v}_{\mathrm{i}} \sim$ iid $\mathrm{N}\left(0, \sigma_{v}^{2}\right), \mu_{\mathrm{i}}$ is more than $0, v_{i}$ and $\mu_{\mathrm{i}}$ are dependent from each other, and $\operatorname{cov}\left(\mathrm{v}_{\mathrm{i}}, \mu_{\mathrm{i}}\right)=0$. In demonstration, because ${ }^{-\mu_{\mathrm{i}}}$ is more than 0, distribution of ${ }^{-\mu_{\mathrm{i}}}$ can use Half-Normal, Exponential, Truncated Normal or Gamma. Because ${ }^{\mu_{\mathrm{i}}}$ and ${ }^{x_{i}}$ may have the endogenous problem. Therefore, in demonstration, formula (2) generally utilizes Maximum Likelihood Estimation (MLE) to estimate. Affected by the random error $\mathrm{v}_{\mathrm{i}}$, actual primary market pricing centers on Stochastic Frontier Analysis Model $f\left(\mathrm{x}_{\mathrm{i}} ; \beta\right)-\mu_{i}$, and fluctuates at random. Insufficient $\mu_{\mathrm{i}}$, which is measurement technique with unilateral distribution, determines that actual pricing is less than or equal with maximum pricing frontier $f\left(\mathrm{x}_{\mathrm{i}} ; \beta\right)$.

After estimating formula (2) with MLE, ${ }^{\beta_{j}}$ that is a model parameter can be obtained. By making use of $\beta_{j}$, frontier issuance pricing of every share can be calculated, $E\left(\mathrm{p}_{\mathrm{i}} \mid \mathrm{u}_{\mathrm{i}}==0, x_{i}\right)$. Primary market issuance pricing efficiency of every share's related influencing factors can be calculated by the following formula:

$$
\mathrm{EFF}_{\mathrm{i}}=\frac{E\left(\mathrm{q}_{\mathrm{i}} \mid \mathrm{u}_{\mathrm{i}}, x_{i}\right)}{E\left(\mathrm{q}_{\mathrm{i}} \mid \mathrm{u}_{\mathrm{i}}==0, x_{i}\right)}
$$


In formula (2), when the explained variable $\ln \mathrm{p}_{\mathrm{i}}$ and explaining variable $\ln \left(\mathrm{x}_{\mathrm{ji}}\right)$ in model appear in the logarithmic form, efficiency of impacting IPO pricing factors is $E F F_{i}=\exp \left(-u_{i}\right)$. The paper uses stata12.1 to estimate Stochastic Frontier Analysis Model.

Variable Statistical Description: The paper divides four stages in research samples in according with three issuing systems in inquiry system. To be specific: first stage is from June 2006 to September 2008. The second stage is from June 2009 to October 2010, excluding financial listed companies. The third stage is from November 2010 to May 2012. This stage mainly contains 166 listed companies. The fourth stage is from May 2012 to October 2012. This stage mainly includes 28 listed companies.

Table 1 IPO Under-pricing Rate Statistical Description of SMEs Board’s Four Stages

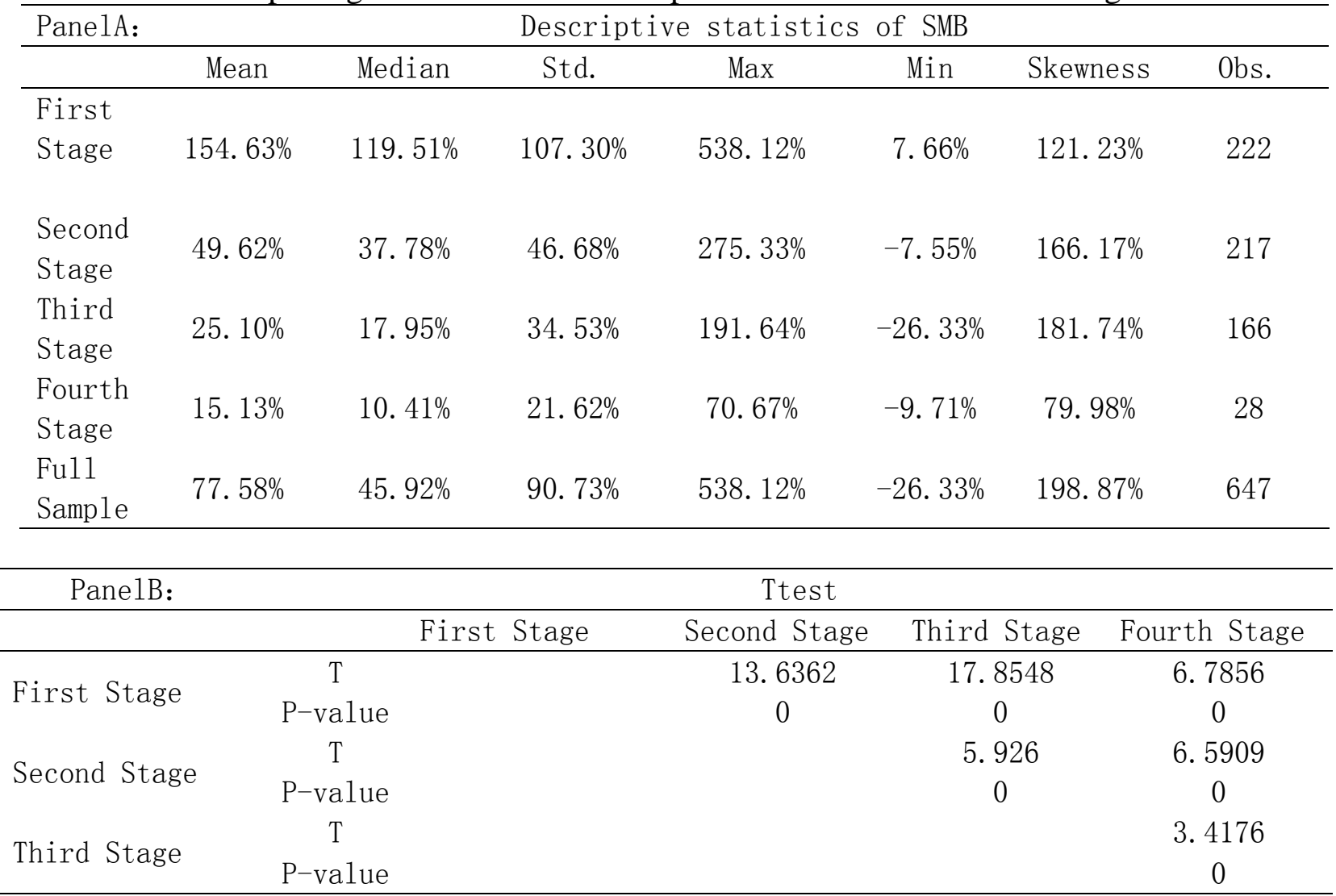

Data source: CSMAR, drawn from settling stata12.1 analysis.

\section{Empirical Results of Primary Market's Pricing Efficiency Before and After Three Reforms in Inquiry System}

Empirical Inspection Results: The paper conduct a research on primary market's pricing efficiency by referring to Hunt, Koh and Francis (1996) to use the SFA log-linear model, and specific expression is as follow:

$$
\begin{aligned}
\ln \left(\text { op }_{\mathrm{i}}\right)= & \beta_{0}+\beta_{1} \ln \left(\text { age }_{\mathrm{i}}\right)+\beta_{2} \ln \left(\text { indpe }_{\mathrm{i}}\right)+\beta_{3} \ln \left(\text { eps }_{\mathrm{i}}\right)+\beta_{4} \ln \left(\text { tasset }_{\mathrm{i}}\right) \\
& +\beta_{5} \ln \left(\text { naps }_{\mathrm{i}}\right)+\beta_{6} \ln \left(\mathrm{plev}_{\mathrm{i}}\right)+\beta_{7} \ln \left(\text { size }_{\mathrm{i}}\right)+\mathrm{v}_{\mathrm{i}}+\mathrm{u}_{\mathrm{i}}
\end{aligned}
$$

Use stata12.1 frontier command. Moreover, assume that disturbing term ${ }^{-\mu_{\mathrm{i}}}$, which measures inefficiency, complies with Half-Normal, conduct Maximum likelihood Estimation(MLE) on SFA model(4).

SFA's estimated results of overall samples are shown as Table 3. Relevance of various explaining variables is corresponding to planned results in references. It can be observed from Table 3 that likelihood ratio test of $\mathrm{H} 0$ : $\sigma_{u}^{2}=0$ refuses the original hypothesis under $1 \%$ significance level. It 
indicates that for overall samples, primary market pricing is not fully efficient. There is deliberate underpricing in primary market. Through $\mathrm{EFF}_{\mathrm{i}}=\exp \left(-\mathrm{u}_{\mathrm{i}}\right)$, average pricing efficiency of overall samples can be calculated as $74.02 \%$.

Table 2 SFA's Estimated Results of Overall Samples

\begin{tabular}{cccc}
\hline Variables & coeffs. & Z & P_value \\
\hline lg(age) & $0.038^{*}$ & 1.84 & 0.07 \\
$\ln$ (indpe) & $0.725^{* * *}$ & 9.98 & 0 \\
$\ln$ (eps) & $0.876^{* * *}$ & 22.14 & 0 \\
$\ln$ (tasset) & $0.06^{*}$ & 1.63 & 0.1 \\
$\ln$ (naps) & 0.079 & 1.35 & 0.18 \\
$\ln$ (plev) & -0.203 & -3.68 & 0 \\
$\ln$ (size) & 0.042 & -0.91 & 0.36 \\
Const & 0.848 & 1.89 & 0.06 \\
\hline /lnsig2v & -2.501 & -14.01 & 0 \\
/lnsig2u & -1.768 & -6.86 & 0 \\
\hline sigma_v & 0.286 & & \\
sigma_u & 0.413 & & \\
sigma2 & 0.253 & & \\
lambda & 1.443 & & \\
\hline L-r test of sigma_u=0 & & \\
$=0.001$ & &
\end{tabular}

Note: $*, * *, * * *$ indicate the $10 \%, 5 \%$ and $1 \%$ significance level, respectively.

SFA's estimated results of subsamples divided in three issuing system reforms in inquiry system are shown as Table 4 . The estimated value of issue price obtained by primary market issuance pricing and Stochastic Frontier Analysis Model is shown as Table 1. By comparing with estimated results of four subsamples, it can find that earnings per share (EPS) have significant positive correlation with issue price in every stage. It indicates that when primary market's institutional investors conduct IPO pricing, earnings per share is are an important reference factor. Industrial average price-earnings ratio has significant positive correlation with IPO issue price in four stages. It is relevant to control issue price by using industrial price-earnings ratio in supervision department for a long time.

SFA's estimated results of subsamples in first stage indicate that the LR test refuses original hypothesis $\mathrm{H} 0: \sigma_{u}^{2}=0$. It shows that primary market has deliberate underpricing in first stage. Primary market's pricing average efficiency is $82.05 \%$. On the other hand, in subsamples of second and third stage, the LR test can't refuse original hypothesis H0: $\sigma_{u}^{2}=0$. It shows that IPO issuance pricing reaches the frontier of pricing efficiency. There is no deliberate underpricing behavior in primary market. SFA's estimated results of subsamples in fourth stage indicate that the LR test refuses original hypothesis H0: $\sigma_{u}^{2}=0$. It shows that after the third issuing system reform in inquiry system, IPO primary market's pricing efficiency is insufficient. There may be deliberate underpricing in primary market.

It can be observed from issuing system reform launched in May 2012 that the supervision department, as a matter of fact, sets up an "upper limit" to IPO issue price, namely price-earnings ratio calculated by IPO issue price can’t exceed $25 \%$ of industrial average price-earnings ratio. If it exceeds this price ceiling, China Securities Regulatory Commission can ask it to enquiry again. Statistical results of research samples also indicate that IPO issue earnings ratio is under the "upper limit" stipulated by China Securities Regulatory Commission. Under the circumstances, in third issuing system reform of inquiry system, actually, it stipulates an "upper limit" to IPO primary market issue price, which may be the cause of resulting in deliberate underpricing in fourth stage's primary market pricing. 
Table 3 SFA's Estimate Results of Subsamples Divided in Issuing System Reform in Inquiry System

\begin{tabular}{|c|c|c|c|c|c|c|c|c|}
\hline & \multicolumn{2}{|c|}{ First Stage } & \multicolumn{2}{|c|}{ Second Stage } & \multicolumn{2}{|c|}{ Third Stage } & \multicolumn{2}{|c|}{ Fourth Stage } \\
\hline Variables & coeffs. & Z & coeffs. & Z & coeffs. & Z & coeffs. & Z \\
\hline $\ln$ (age) & -0.014 & -0.65 & -0.032 & -1.46 & 0.024 & 0.69 & -0.157 & -1.45 \\
\hline ln(indpe) & $0.292^{* * *}$ & 4.96 & $0.549^{* * *}$ & 4. 64 & $0.959^{* * * *}$ & 7.85 & $0.756^{* *}$ & 2.24 \\
\hline $\ln ($ eps $)$ & $0.768^{* * *}$ & 21.64 & $0.919^{* * * *}$ & 22.27 & $0.777^{* * * *}$ & 11.22 & $0.398^{* *}$ & 2. 40 \\
\hline $\ln ($ tasset) & 0.009 & 0.25 & 0.029 & 0.82 & -0.081 & -1.09 & 0.044 & 0.26 \\
\hline ln (naps) & -0.029 & -0.49 & $-0.107^{*}$ & -1.88 & -0.005 & -0.05 & 0.192 & 0.71 \\
\hline $\ln (\mathrm{plev})$ & 0.020 & 0.33 & $-0.104^{* *}$ & -0.19 & $0.159^{*}$ & 1.62 & -0.167 & -2.11 \\
\hline $\ln (\operatorname{size})$ & -0.056 & -1.60 & -0.044 & -1.06 & 0.023 & 0.21 & -0.279 & -1.27 \\
\hline Const & $2.152^{* * *}$ & 5.65 & $1.953^{* * *}$ & 3.03 & -0.278 & -0.33 & 2. 464 & 1.36 \\
\hline /lnsig2v & $-3.684^{* * *}$ & -18.05 & $-3.023^{\text {*** }}$ & -31.17 & $-2.823^{* * *}$ & -7.85 & $-2.11^{* * *}$ & -8.56 \\
\hline /nsig2u & $-2.618^{* * * *}$ & -11.21 & -11.293 & -0.08 & $-2.743^{\text {*** }}$ & -2.97 & $-1.956^{* * *}$ & -3.41 \\
\hline sigma_v & 0.158 & & 0.221 & & 0.244 & & 0.348 & \\
\hline sigma_u & 0.270 & & 0.004 & & 0.254 & & 0.376 & \\
\hline sigma2 & 0.098 & & 0.049 & & 0.124 & & 0.263 & \\
\hline lambda & 1.705 & & 0.016 & & 1. 041 & & 1.081 & \\
\hline $\mathrm{L}-\mathrm{r}$ test & 11.070 & & 0.000 & & 0.540 & & 1.590 & \\
\hline $\begin{array}{l}\text { Prob }>=\text { chibar } \\
2\end{array}$ & 0.000 & & 1. 000 & & 0.232 & & 0.090 & \\
\hline
\end{tabular}

Note: *,**, *** indicate the $10 \%, 5 \%$ and $1 \%$ significance level, respectively.

Figure 1 Stochastic Frontier Boundary of Four Stages in SMEs Board’s Inquiry System
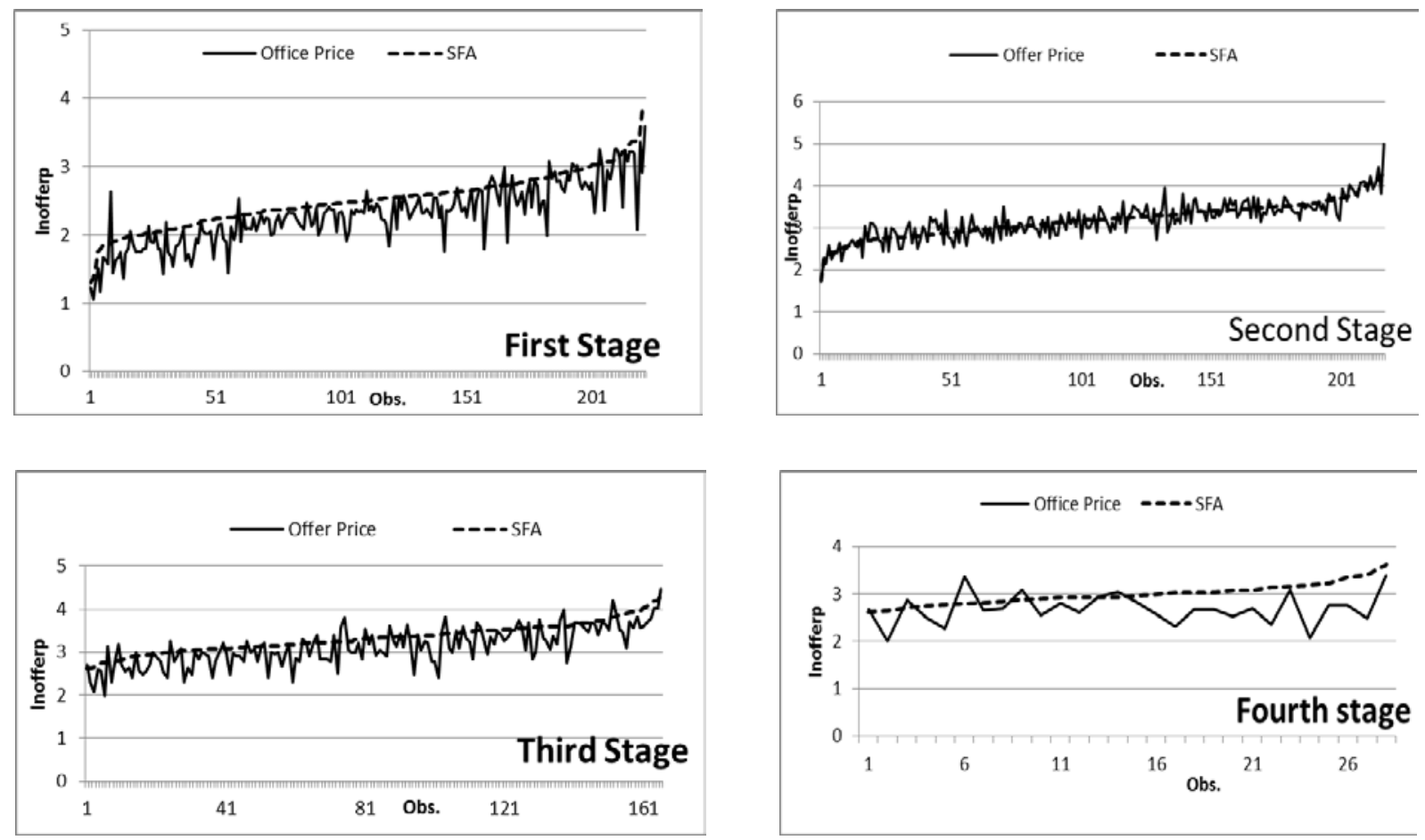

The Robustness Test: In conducting SFA, because there is no unique and recognized selection in the model of $\operatorname{lnq}_{\mathrm{i}}=\beta_{0}+\sum_{\mathrm{j}=1}^{k} \beta_{j} \ln \left(\mathrm{x}_{\mathrm{ji}}\right)+\mathrm{v}_{\mathrm{i}}-\mu_{\mathrm{i}}$, it needs to conduct the robustness test on the possible influence factor $\mathrm{x}$. The paper utilizes current ratio to replace asset-liability ratio, makes use of main business income of the year before issuing to replace total assets before issuing, uses SMEs board's (399005) closing index to replace industrial average price-earnings ratio, and adds net assets income rate the 
year before issuing, as well as the dummy variable of underwriters' reputation, so as to conduct the robustness test on the SFA model. Table 5 is the result of robustness test. It can be observed from the table that after replacing and adding some new or suitable variables conforming to economic meanings, the entire SFA's estimated results don't reverse and are similar to previous estimated results.

Table 4 The Robustness Test on Overall Samples

\begin{tabular}{|c|c|c|c|}
\hline Variables & coeffs. & Z & P_value \\
\hline $\ln ($ age $)$ & 0.016 & 0.92 & 0.36 \\
\hline $\ln ($ index $)$ & $0.818^{* * *}$ & 19.82 & 0 \\
\hline $\ln (\mathrm{eps})$ & $0.589^{* * * *}$ & 10.81 & 0 \\
\hline $\ln$ (income) & 0.019 & 1 & 0.32 \\
\hline ln (naps) & $0.244^{* * * *}$ & 4. 19 & 0 \\
\hline $\ln (1 \mathrm{db})$ & $0.119^{* * * *}$ & 4. 29 & 0 \\
\hline $\ln ($ size $)$ & -0.043 & -1.43 & 0.15 \\
\hline $\ln ($ roe $)$ & $0.206^{* * *}$ & 3.93 & 0 \\
\hline reputation & -0.007 & -0.28 & 0.78 \\
\hline Const & $-4.5^{* * * *}$ & -9.89 & 0 \\
\hline /lnsig2v & $-2.807^{* * * *}$ & -15.58 & 0 \\
\hline /lnsig2u & $-2.190^{* * *}$ & -7.62 & 0 \\
\hline sigma_v & 0.246 & & \\
\hline sigma_u & 0.335 & & \\
\hline sigma2 & 0.172 & & \\
\hline lambda & 1. 362 & & \\
\hline
\end{tabular}

Note: ***,*** indicate the $10 \%, 5 \%$ and $1 \%$ significance level, respectively.

\section{Conclusions}

The paper utilizes 647 SMEs board's IPO listed companies from June 2006 to November 2012 to regard as research samples, makes use of Stochastic Frontier Analysis Model to conduct an empirical study on primary market's pricing efficiency in inquiry system. The results show that: (1) for overall samples, there is deliberate underpricing in our country's primary market pricing after inquiry system. Primary market pricing still deviates from price ceiling estimated Stochastic Frontier Analysis obviously.

(2) Three reforms in accordance with IPO issuing mechanism of inquiry system stage, overall samples are divided into four stages. Every stage's primary market pricing conducts Stochastic Frontier Analysis estimation. The estimated results show that management's "window operation” on primary market IPO pricing will result in primary market pricing's incomplete efficiency, while after canceling this "window operation”, primary market pricing is efficient. There is no deliberate underpricing behavior.

\section{References}

[1] Bai Zhongguang and Zhang Wei, 2003,The IPO Short-Term Yield Research Based on Pricing Model of Stochastic Boundary[J], Journal of Management Science, No. 2: pp51-59.

[2] Chen Yanli and Cao Guohua, 2010, The Source Research on IPO Underpricing Based on Stochastic Frontier Analysis’s Growth Enterprise Market (GEM) [J], Technical Economy, Vol.129, No.12:pp32-32.

[3] Qiu Dongyang and Xiong Weiqin, 2011, IPO Underpricing Decomposition Based on Stochastic Frontier Analysis [J], Journal of Chongqing University of Technology, Vol.25 No.11: pp50-56. 
[4] Liu Yuhui and Shen Keting, 2011, Is It Primary Market Underpricing, or Secondary Market Underpricing----A Test and Explanation on Our Country's IPO Higher Underpricing [J], Journal of Financial Research, No.11: pp183-196.

[5]M. J. Farrell, 1957, The Measurement of Productive Efficiency [J], Journal of the Royal Statistical Society. Series A (General) Vol. 120, No. 3, pp. 253-290

[6]D. J. Aigner and S. F. Chu, 1968, On Estimating the Industry Production Function [J], The American Economic Review Vol. 58, No. 4, pp. 826-839

[6]Chen, Hung and Wu, 2002, The Underpricing and Excess Returns of Initial Public Offerings in Taiwan Based on Noisy Trading: A Stochastic Frontier Model [J], 18:139-159

[7]Hunt-McCool J.,Koh S.C.,and Francis B.B.,1996,Testing for Deliberate Underpricing in the IPO Premarket: A Stochastic Frontier Approach[J], Review of Financial studies, Vol.(4):1251-1269 